\title{
O Primado do Reconhecimento sobre a Redistribuição: a origem dos conflitos sociais a partir da teoria de Axel Honneth
}

NADIA LUEIA FUHRMANN"

\section{Resumo}

O artigo tem por objetivo precípuo socializar o estudo empreendido na Teoria do Reconhecimento, do sociólogo e filósofo alemão Axel Honneth, em estágio pós-doutoral no Núcleo de Pesquisa "Violência e Cidadania", no Programa de Pós-graduação em Sociologia, da UFRGS, no período 2010-2011. A meta foi articular a pesquisa teórica sobre o "reconhecimento intersubjetivo e social" com uma investigação empírica qualitativa sobre as origens do fenômeno de rualização infanto-juvenil, no meio urbano. A hipótese preconizou o primado do reconhecimento negado a crianças e jovens em situação de vulnerabilidade social, em detrimento de condições econômicas desfavoráveis, como causa da migração para a vida nas ruas e da ocorrência dos múltiplos conflitos sociais deflagrados por essa condição. A pesquisa de campo foi realizada em parceria com duas instituições assistenciais de Porto Alegre, que oferecem o Serviço de Apoio Socioeducativo (SASE), conveniadas com a prefeitura municipal. Os resultados corroboraram a hipótese de que as políticas públicas de distribuição de renda desarticuladas das práticas assistenciais e educativas não contribuem para arrefecer as conflitualidades urbanas. Nesse sentido, o Programa SASE, voltado ao atendimento de crianças e jovens das classes populares que vivenciam diuturnamente a desestrutura-

\footnotetext{
*Socióloga e Doutora em Serviço Social. Doutorado sanduíche na Universität-Kassel, Alemanha. Pós-doutorado no Programa de Pós-graduação em Sociologia da Universidade Federal do Rio Grande do Sul (Brasil). E-mail: fuhrmann.nadia@gmail.com.
} 
ção familiar, o abandono afetivo, moral, intelectual e o desprezo social, contribui para o fortalecimento das três dimensões do reconhecimento: o amor, o direito e a estima social, reintegrando o público alvo ao núcleo familiar e à sociedade.

Palavras-chave: Teoria do Reconhecimento. Conflitualidades. Rualização. SASE.

\section{The primacy of recognition over redistribution: the origin of social conflicts in Honnethian theory}

\section{Abstract}

The article's main purpose is to socialize the study undertaken in the Theory of Recognition of the German sociologist and philosopher Axel Honneth, in a postdoctoral Research Center on "Violence and Citizenship" in the Graduate Program in Sociology, from UFRGS, in 2010-2011 period. The goal was to articulate the theoretical research about the "intersubjective and social recognition" with a qualitative empirical research on the origins of the phenomenon of street-living children and youth in urban areas. The hypothesis proposed the primacy of recognition denied to children and youth in situations of social vulnerability in contrast to the argument of unfavorable economic conditions as a main cause of migration to the street life and the occurrence of multiple social conflicts started by this condition. The field research was conducted in partnership with two assistential institutions in Porto Alegre, which offer the Social Educational Support, in agreement with the city government. The results corroborate our hypothesis by showing the inadequacy of public policies on income distribution and social inclusion implemented in a disjointed front of assistential and educational practices, that doesn't contribute alone to decrease urban conflictualities. In this sense, the SASE program, aimed at assisting children and young people from lower classes who experience daily family disintegration, affective abandonment, moral, intellectual and social contempt, contributes to the strengthening of the three dimensions of recognition: love, law and social esteem, reinstating these people to families and society.

Key-words: Theory of Recognition - conflictualities - street-living - Social Educational Support 


\section{Introdução}

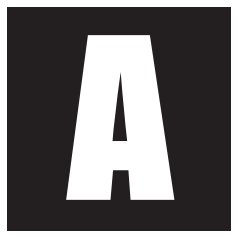

complexidade das relações, interações e ações sociais, a partir dos últimos 30 anos, tem forçado contundentemente os cientistas sociais a reconstruírem grande parte do seu conhecimento acumulado durante séculos. O labor sociológico, em tempos de hipermodernidade, cada vez mais, tem privilegiado as práticas e intervenções sociais em oposição à postura secular de observação, explicação e elaboração de conhecimento. Hodiernamente, a sociologia está totalmente em consonância com a cotidianidade humana, colaborando, em especial, com soluções para a diversidade das patologias sociais oriundas dessa complexificação das relações humano-sociais. Só assim, ela tem cumprido com eficiência seu papel enquanto ciência da sociedade. Tavares dos Santos (2005, p. 220221) exemplifica essa premissa quando escreve que:

as transformações sociais e as urgências da vida coletiva fazem com que os grupos sociais peçam saberes sociológicos para explicar os processos sociais e históricos (...) as novas questões sociais constituem um vasto campo de interrogações à prática sociológica (Tavares dos Santos, 2005, p. 220-221).

Dentre as múltiplas urgências que permeiam a sociedade contemporânea, as lutas e os conflitos urbanos têm sido um dos maiores desafios para a Sociologia, todavia, tardiamente estudados com profundidade por esta no Brasil. Segundo Misse (2006), a temática sobre as violências começa a ser sistematicamente investigada pela Sociologia brasileira a partir da década de 1970.

Há vinte anos publicava-se no Rio de Janeiro uma pesquisa pioneira de que participei "Delinquência Juvenil na Guanabara: uma introdução sociológica". Lembro-me que quando começamos, em 1971, não havia praticamente 
nada na sociologia brasileira sobre o assunto, nem mesmo sobre a questão que hoje é tratada como "violência urbana", "criminalidade", etc. O interesse por essa temática era igualmente nulo na antropologia e historiografia, e as raras incursões no assunto, encontráveis à época, restringiam-se a abordagens provenientes das áreas de Educação e Serviço Social (Misse, 2006, p. 1).

O que parece positivo é uma tendência atual de múltiplos estudos que permitem conhecer o fenômeno sob os mais diversos ângulos, num movimento de complementaridade. Neste aspecto, Tavares dos Santos (2011, p. 413) lembra que essa empreitada necessita de um olhar sociológico transdisciplinar. Também Saramago diria que (...) para realmente conhecer as coisas, há que dar- Ihes a volta, dar-Ihes a volta toda. O certame é desenvolver um conceito aproximado de "conflitos sociais contemporâneos" a partir da necessária transversalidade disciplinar.

Trata-se, contudo, neste artigo, da socialização dos procedimentos metodológicos e de resultados parciais de um estudo empreendido no Núcleo de Pesquisa "Violência e Cidadania", dentro do Programa de Pósgraduação em Sociologia da Universidade Federal do Rio Grande do Sul, no período entre 2010 e 2011, com apoio do CNPq. O tema investigado trata da rualização de crianças e jovens e as múltiplas formas de violência a que esses estão expostos, um fenômeno com incidência expressiva ${ }^{\square}$ na capital rio-grandense. Estudos sobre esse objeto já foram realizados no Programa de Pós-graduação em Sociologia da UFRGS, porém, priorizando os dados quantitativos, de modo que este tem como particularidade o uso exclusivo de procedimentos metodológicos qualitativos e como sustentação teórica a Teoria do Reconhecimento Intersubjetivo e Social do sociólogo e filósofo alemão Axel Honneth. Ainda parece adequado ressaltar a importante produção de conhecimento realizada pelos pesquisadores do Núcleo de Pesquisa "Violência e Cidadania", em 20 anos de 
atividade na Universidade Federal do Rio Grande do Sul, subsídio fundamental para a realização deste trabalho.

O tema "irresidência infanto-juvenil" é deveras amplo, carecendo de um recorte da própria matéria aliado à delimitação geográfica e espacial do objeto. Como acima já sublinhado, o fenômeno é competente e recorrentemente abordado pela Sociologia brasileira, de forma que, considerando a premissa científica da originalidade necessária para o mérito de novas pesquisas, privilegiamos uma perspectiva de caráter qualitativo, aliando o estudo teórico às investigações empíricas do objeto, com pretensão secundária a uma intervenção assistemática. Por intervenção assistemática, entendemos a pesquisa de campo em relação direta com os sujeitos pesquisados, podendo tal conexão resultar em uma pesquisa ativadora da consciência. Isso ocorre, na medida em que se desenvolve um diálogo entre o pesquisador e os sujeitos da pesquisa. Os últimos, ao falarem de seu cotidiano, passam a refletir sobre ele. Por sua vez, obter uma resposta relativa aos resultados de uma pesquisa ativadora só poderia ser auferido num segundo plano da investigação, a depender de um prazo para a reflexão sobre a experiência do encontro entre o pesquisador e os sujeitos pesquisados.

Em relação à fundamentação teórica, houve uma revisão da obra de Axel Honneth, a partir da qual, talhamos um projeto cuja hipótese principal considerou que o recrudescimento da violência e dos conflitos urbanos envolvendo crianças e adolescentes tinha como principal causa falhas no processo de formação do Reconhecimento Intersubjetivo e Social que supõe o fortalecimento das esferas psico-políticas-sociais representadas pelo amor, pelo direito e pela estima social. A exclusão e a vulnerabilidade social, motivos principais da rualização de crianças e jovens, não estariam relacionadas isoladamente à inópia material, mas a ausência de reconhecimento intersubjetivo e social. Dito de outra forma, seriam as 
experiências de não reconhecimento social as principais causas de "irresidência" e dos conflitos urbanos, envolvendo o segmento infanto-juvenil.

A investigação, porém, não privilegiou o que se convencionou chamar de situação de "rua moradia" ou de "rua sobrevivência", mas procurou desvendar as estratégias político-sociais que estariam colaborando na minimização ou quiçá na erradicação do fenômeno antes mesmo de sua efetivação e consequências. De imediato, o estudo sobre a alternativa da institucionalização, não raramente empregada para retirar tal segmento das ruas, foi descartado. A pesquisa alumiou o campo da prevenção, que, neste caso, ocorre por meio de programas públicos assistenciais já existentes. Esses programas se dedicam às atividades de ensino não formal, cujo conteúdo pauta o cuidado afetivo, a formação cognitiva e moral, também o fortalecimento do amor-próprio e da autoestima. Tais práticas pedagógicas, em sua continuidade, parecem contribuir no arrefecimento das vulnerabilidades dessas crianças e jovens, abrandando as situações de "rualização" e de conflitos.

Nesse sentido, o fio condutor subjacente à explicação de tal fenômeno sociológico desde um enfoque não materialista, assim como a experimentação da hipótese contemplaram, de um lado, a Teoria do Reconhecimento de Axel Honneth e, de outro, os procedimentos metodológicos amparados nas técnicas e instrumentais da investigação qualitativa. Isto é, a interpretação das narrativas biográficas dos sujeitos profissionais e beneficiários da política assistencial conhecida como Serviço de Apoio Socioeducativo (SASE), voltada para uma educação não formal de crianças e jovens das classes populares. 


\section{As Etapas do Processo Metodológico}

Para desenvolver o estudo, elegemos como metodologia o modelo de investigação qualitativa de Lessard-Hébert e coautores (2005). Segundo esses, uma pesquisa qualitativa reivindica a construção de quatro polos, a saber: um polo epistemológico, que torna clara a visão de mundo do investigador, por meio do discurso empregado por ele ao nomear o seu objeto; um polo teórico, que propicia a definição dos conceitos e a testagem da hipótese; um polo técnico, que corresponde à feitura dos instrumentos e técnicas de coleta e análise do material da investigação; certamente essa é a instância de articulação das explicações sobre o objeto percepcionado com a realidade vivida; e, por fim, um polo morfológico ou comunicativo, que prevê os meios de socialização dos resultados da investigação, ou seja, a organização, apresentação e exposição dos resultados.

Por tratar-se de pesquisa qualitativa, os caminhos percorridos para a realização do estudo carecem de pormenorizada descrição. O polo epistemológico, como ponto de partida, privilegiou a hermenêutica filosófica por se constituir em um desses esteios para as pesquisas que buscam o significado e o sentido das atividades do homem. O hermeneuta toma para si a tarefa de buscar a verdade por meio da pré-compreensão da história e da cultura dos sujeitos e do diálogo argumentativo com estes por meio da linguagem. São duas fases indissociáveis da investigação. A hermenêutica parte do princípio de que não há sujeito sem pré-conceito. O investigador tem a consciência de que o prejuízo sobre os objetos é imanente ao ser humano. Por isso, o conhecimento autêntico das manifestações humanas não pode ocorrer sem a comunicação. Na conversação é que se dissipam os preconceitos. Por meio da conversa é que o investigador desvenda as significações da produção e da prática humana. 
Certamente, a frase mais conhecida de Gadamer é o ser que pode ser compreendido é linguagem (1990, p. 478). Isso significa que o mundo que podemos apreender só se desvenda no bojo de conteúdos linguísticos. Lawn (2007, p. 113) diz que Gadamer contestaria qualquer opinião sobre o entendimento que pressupõe algo não linguístico. Aquilo que não pode ser expresso por palavras só poderá ser parcialmente compreendido. Isso porque a linguagem não se constitui em instrumento passível de manipulação - e é no diálogo desvendada. Gadamer não nega a existência das manifestações humanas alinguísticas, o não dito, porém, esse não pode explicar e entender totalmente o ser (Lawn, 2007, p. 112).

Em complementação, para construir o polo teórico, buscamos referências na obra de Axel Honneth. Objetivamos extrair dos escritos desse autor os fundamentos de compreensão, interpretação e intervenção para o fenômeno da "rualização" de crianças e jovens em situação de vulnerabilidade social, articulando-os com uma pesquisa empírica. Esta teve o propósito de verificar a contribuição do Serviço de Apoio Socioeducativo (SASE), da prefeitura de Porto Alegre, no processo de resgate do reconhecimento intersubjetivo do público-alvo, e uma potencial contribuição no retrocesso da "irresidência" e de conflitualidades envolvendo o segmento infanto-juvenil.

A criança de rua é definida pelas Nações Unidas como "qualquer menino ou menina para quem a rua tornou-se moradia habitual e/ou fonte de sobrevivência; e que não tem a proteção, supervisão ou orientação adequada de um adulto responsável" (Lusk e Mason, 1993, p. 157). Consideramos como criança aquela que possui entre 0 e 12 anos (incompletos), e adolescente (jovens) o que tem entre 12 e 18 anos (incompletos), conforme inscrito no Estatuto da Criança e do Adolescente (Sabatovski; Fontoura, 2010). Portanto, entendemos por "crianças e adolescentes em situação de rua" aqueles que são identificados pela sociedade, pelas ins- 
tituições governamentais e pelas organizações sociais dentro dos parâmetros acima definidos.

Pela própria complexidade imanente do fenômeno, reiteramos que o mesmo exige conhecimentos e respostas de cunho interdisciplinar. Assim, novas abordagens teóricas podem vir a ser importantes contribuições e, dentre essas, a de Axel Honneth tem chamado atenção especial no meio acadêmico brasileiro. A denominada Teoria do Reconhecimento Intersubjetivo e Social se fundamenta nos estudos da formação da identidade, realizados por George Herbert Mead (1863- 1931), e nas premissas universais de reconhecimento social de Georg W. Friedrich Hegel (1770- 1831). Segundo Honneth, o desenvolvimento teórico da noção de Reconhecimento ficou no nível do idealismo em Hegel, enquanto a contribuição de Mead possibilitou a compreensão empírica da questão do Reconhecimento intersubjetivo dos indivíduos. Portanto, para compor sua teoria, Honneth se vale (1) da noção hegeliana original, que entende a luta por respeito e reconhecimento intersubjetivo como a origem dos conflitos sociais e (2) a afirmação de Mead de que a identidade dos sujeitos está vinculada à experiência do reconhecimento intersubjetivo. No entanto, diz Honneth, nem Hegel, nem Mead foram capazes de explicar as formas de desrespeito que tornam a experiência do não reconhecimento o motor para os conflitos sociais. De forma geral, a tese central de Honneth aponta que a identidade dos indivíduos se determina em um processo intersubjetivo mediado pelo mecanismo do reconhecimento. A busca pelo reconhecimento é imanente a todo o ser humano, desde o seu nascimento, e se realiza efetivamente através das dimensões do amor, do direito e da solidariedade. A ausência de reconhecimento intersubjetivo e social corresponde à verdadeira origem dos conflitos sociais, tese oposta às que propõem a precariedade econômica como causa principal da violência e dos desajustes sociais, apontando como solução a mera 
redistribuição de recursos materiais. Para Honneth, inversamente, são as experiências de ausência de afeto na primeira infância e a humilhação e invisibilidade social geradoras dos impulsos agressivos e sentimentos de vingança, contra si mesmo e/ou contra a sociedade.

A formação de uma identidade prática socialmente sadia deriva do desenvolvimento humano amparado numa esfera emotiva positiva (confiança em si mesmo adquirida na infância na relação com a mãe e/ou cuidadores); noutra esfera de estima, dentro da sua comunidade (porque sem a solidariedade estaria o sujeito exposto à degradação social) e, por fim, em uma esfera jurídica (relacionada ao autorrespeito enquanto sujeito de direitos e deveres). A ausência dessa estrutura de reconhecimento, segundo Honneth, desencadeia o aviltamento do indivíduo e a deflagração dos desajustes e patologias sociais (Honneth, 2009).

Honneth (2009b, p. 24-30) explicita as três formas de menosprezo as quais os sujeitos estão expostos na vida em sociedade e apresenta os modelos correspondentes de reconhecimento. Assim, a primeira experiência de humilhação que um indivíduo pode sofrer se refere à negligência, tortura e violação de direitos. A forma mais básica do não reconhecimento é a negação do afeto e do respeito. A consequência é a insegurança emocional e física, uma fratura na autoconfiança que se constitui na premissa psíquica para o desenvolvimento de todas as demais formas de autoestima. A segunda forma de menosprezo se refere à privação de direitos e à exclusão social. Neste caso o indivíduo é humilhado socialmente, por não ter garantidos os seus direitos e ter ignorado seus deveres. $\mathrm{O}$ direito assegura ao homem/mulher uma ampliação das suas liberdades individuais, independentemente da classe social a que pertença, arrefecendo as desigualdades e promovendo o autorrespeito. Os impedimentos para o pleno exercício da cidadania resultam na invisibilidade social do indivíduo. Assim, o terceiro tipo de menosprezo é a degradação 
social - quando o indivíduo não obtém da sua comunidade a aprovação solidária e a apreciação das capacidades e formas de vida desenvolvidas individualmente (Honneth, 2009b, p. 28). O sujeito que não obtiver a aprovação intersubjetiva e social do seu modo de vida, se ele não se sente valorizado pelo seu grupo de convivência familiar e institucional, ele não desenvolve o sentimento de autoestima necessário para o convívio em sociedade. São estes três modelos de reconhecimento, segundo o autor, que estabelecem as condições formais de interação através das quais os homens/mulheres podem ver garantida a sua dignidade ou integridade. Dito de outra forma, a ausência desses três modelos de reconhecimento comprometem a autoconfiança, o autorrespeito e a autoestima, sem os quais os sujeitos não se realizam social e individualmente de forma plena. A busca pelo reconhecimento negado ocorre, então, através da revolta, das pressões e da violência, originando os conflitos individuais e sociais.

Seguindo a linha argumentativa de Honneth, as patologias sociais se desenvolvem em ambientes socialmente injustos, mas que não se originam de circunstâncias materiais; ao contrário, quando alguns indivíduos ou todos de uma determinada sociedade não conseguem compreender de modo adequado práticas e normas do reconhecimento, só então se pode falar efetivamente em patologia social (Honneth, 2011, p. 156). A inadaptação às normas sociais, de modo geral, se apresenta na forma de comportamentos de risco, violências e conflitos urbanos, intolerâncias, exclusão e degradação social.

Visto isso, na sequência, o polo técnico compreendeu todo o processo de construção metodológica da investigação. Para fins de tratamento mais organizado, a partir da conclusão do projeto com suas partes constitutivas alinhavadas, partimos para os estágios da operacionalização. Esta incluiu as seguintes tarefas, não necessariamente em ordem consecutiva: levantamento bibliográfico, documental e virtual sobre o tema; 
levantamento de dados e informações junto à Fundação de Assistência Social e Cidadania de Porto Alegre e duas Instituições que oferecem o SASE, doravante denominadas Instituição A e Instituição B; construção dos instrumentos de coleta de informações: roteiros para os grupos focais; depoimentos (entrevistas semiestruturadas) para profissionais envolvidos com o SASE; depoimentos (entrevista semiestruturada) para alunos participantes e egressos do SASE; organização de grupos focais com os alunos participantes e egressos do SASE com o fim de corroborar/complementar as entrevistas individuais; organização e análise do material primário, secundário e narrativo. Os sujeitos da pesquisa foram os coordenadores do Programa SASE (dois), os alunos participantes do Programa SASE (treze), os egressos do SASE (nove), profissionais (quatro) e educadores sociais (quatro), num total de 34 entrevistados. Quando se fala em profissionais, estamos nos referindo aos envolvidos profissionalmente no Projeto SASE, como psicólogos, assistentes sociais e pedagogos. Os alunos participantes foram crianças e adolescentes (06 a 14 anos) inscritos no SASE. As entrevistas com crianças de 06 a 12 anos foram realizadas na presença de responsável da Instituição (educadores sociais ou coordenadores). Os egressos foram adolescentes maiores de 14 anos já desligados do Programa. Isto porque se pretendeu verificar a trajetória pessoal posterior e a influência do Serviço na vida desses jovens. Os Grupos Focais foram necessários para que pudéssemos obter informações de caráter qualitativo em profundidade. A inserção da técnica dos grupos focais em uma abordagem qualitativa permite, também, a construção do conhecimento para o próprio sujeito participante que percebe algo sobre o qual ele tem uma familiaridade. Pode despertar, portanto, no informante, o desejo de conhecer a própria realidade e mais sobre si mesmo. Assim, a investigação qualitativa que utiliza a técnica de Grupos Focais pode ser entendida como uma pesquisa ativadora, ou seja, a própria pesquisa pode ativar 
o processo de reflexão e de mudança nos sujeitos envolvidos no estudo. Dos Grupos Focais, fizeram parte somente os alunos participantes do SASE e os egressos. No caso de material fotográfico, as crianças receberam máscaras de super-heróis e óculos de brinquedo para evitar o borrão no rosto, obrigatório para não identificação. Optamos por não fotografar os adolescentes porque alguns cumpriam medidas socioeducativas em meio aberto e outros conviviam em comunidades extremamente violentas, inclusive envolvendo o tráfico de drogas. Provavelmente, ao fotografá-los, mesmo com artifício de mácula, haveria de influenciar a espontaneidade das respostas.

O material coletado das entrevistas e dos Grupos Focais foi submetido à análise do software NVIVO 8, que se constitui numa ferramenta computadorizada de auxílio à realização de estudos qualitativos, com informações não estruturadas. Concomitante com o resultado do programa informatizado, o material empírico foi submetido à codificação interpretativa dentro de uma orientação hermenêutica e não técnica, também compreendida a partir da percepção do horizonte cultural dos entrevistados. Assim, o resultado final, sempre numa perspectiva limitada e parcial diante da totalidade dos demais estudos já empreendidos sobre o tema, foi fruto da mediação entre a Teoria do Reconhecimento de Axel Honneth e as informações empíricas buscadas nas narrativas dos depoentes. A anonimização foi adotada para a não identificação das instituições pesquisadas e dos sujeitos da pesquisa, no entanto, o contexto e os sentidos foram preservados.

O material empírico foi coletado junto a duas instituições beneficentes de Porto alegre, conveniadas com a FASC, doravante denominadas de instituição $A$ e instituição $B$. A instituição A teve origem na década de 1950, idealizada por uma assistente social que obteve apoio e parceria do Juizado de Menores, da Santa Casa de Misericórdia e do Curso de 
Serviço Social da PUCRS. O objetivo inicial foi amparar e educar adolescentes grávidas e seus filhos, abandonados pela família e pelo Estado, numa época em que mães solteiras e filhos bastardos eram estigmatizados pelo núcleo familiar. Com o passar do tempo, a Instituição foi ampliando suas atividades assistenciais, sempre voltadas para o segmento infanto-juvenil em situação de vulnerabilidade. Atualmente, conta com os serviços de abrigo em turno integral para um público com idades entre 09 e 18 anos incompletos, oriundo de situações sociais precárias, onde as crianças e adolescentes recebem atendimento psicológico, médico, educativo e profissionalizante. Conta, também, com 80 vagas anuais para a educação infantil e uma Casa Lar que oferece acolhimento para a demanda dos conselhos tutelares. Em especial, oferece o programa SASE, em parceria com a Fundação de Assistência Social e Cidadania (FASC).

No seu Plano de Ação 2011, conceitua o SASE como um espaço de proteção, de socialização, desenvolvimento pessoal, social e cognitivo. Oferece 80 vagas para crianças e jovens com idade entre 06 e 15 anos, no turno inverso ao da escola curricular. São cinco turmas, três no turno da manhã e duas no turno da tarde com, no máximo, 16 alunos por sala de aula. Dentre os critérios para ser usuário do Serviço, constam uma situação familiar ou pessoal de vulnerabilidade social, afetiva ou emocional bem como pertencer a um núcleo familiar com precário acesso à renda e a serviços públicos. As famílias devem estar inscritas em programas do governo do tipo bolsa família, abrigos, programa de erradicação do trabaIho infantil, entre outros. Os recursos humanos para o SASE são compostos por uma coordenadora pedagógica com nível superior em pedagogia, quatro educadores com nível médio (sem exigência de especialidade pedagógica específica), uma auxiliar de escritório, uma cozinheira, e um profissional de serviços gerais. A Instituição aceita pessoas voluntárias para a realização de atividades lúdicas e esportivas com as crianças e jovens. 
Oferece um espaço físico que disponibiliza três salas para o atendimento, uma sala de informática, uma biblioteca e uma cozinha equipada. Possui uma área ao ar livre para atividades lúdicas e esportivas. Dos objetivos específicos da Instituição A, destacamos o de desenvolver bons hábitos e atitudes; conhecer, praticar e defender os direitos fundamentais da pessoa humana: a vida, os meios de mantê-la com dignidade, na fraternidade e no bem comum; participar de forma consciente no mundo em que vive, assumindo um posicionamento autônomo diante dos fatos e situações; desenvolver a capacidade de trabalhar em grupo; estimular a prática da cidadania e vivência de valores éticos; desenvolver oficinas lúdicas e significativas para que as crianças e adolescentes possam fazer uma reflexão sobre o mundo em que vivem e se tornem agentes de solidariedade e cidadania; contribuir para a inserção, reinserção e permanência na escola e complementar as ações da família na proteção e desenvolvimento dessas crianças e desses adolescentes. O serviço procura dar uma formação ampla, não fundamentada na transmissão de conhecimentos formais ou na aquisição de valores individuais dos alunos, mas busca numa construção integrada e dinâmica das suas atividades, dialogar com as contradições do cotidiano, enfatizar a proatividade dos comportamentos coletivos no processo de mudança e da transformação social.

Em relação ao conteúdo pedagógico, as aulas contemplam um período para o reforço e o tema curricular. Todavia, não há conteúdo programático predefinido, mas os educadores têm por orientação trabalhar com os seguintes temas: meio ambiente; sexualidade; esporte; crescimento social e educacional; vida saudável; educação para o trânsito e linguagem digital. O trabalho é executado preferencialmente no formato de oficinas, organizado com apoio pedagógico, oficina de leitura, oficina de artes manuais, oficina de esporte e saúde, oficina de recreação livre e dirigida, grupos de socialização e oficina de informática. As atividades assistemáticas 
contam com visitas a museus; arquivo histórico; teatro; cinema; integração com outros SASEs e escolas; parques; praças; Usina do Gasômetro; Casa de Cultura Mario Quintana, entre outros. No intuito de aprimorar o Serviço e qualificar o atendimento às crianças, a Instituição A promove mensalmente reunião com a família das crianças e adolescentes, em que pese, a presença de familiares não se mostrar assídua; reunião com a equipe e avaliação tanto dos educandos quanto dos educadores. Segundo a própria entidade, o impacto social esperado através desse trabalho é que tais crianças e adolescentes se reconheçam como sujeitos de direitos e deveres e que desenvolvam a autoestima necessária para conviver em harmonia em diferentes grupos sociais, desenvolvendo habilidades como a criatividade, autonomia e responsabilidade.

Já a Instituição B teve origem no fim dos anos 1970, idealizada pelos freis franciscanos. $\mathrm{O}$ objetivo inicial foi oferecer acolhimento às crianças de uma comunidade periférica da capital, enquanto seus pais, a maioria oriunda do êxodo rural, cumpriam sua jornada de trabalho semanal. Ainda nesta década e na seguinte, estabeleceu importante parceria com duas instituições assistenciais alemãs, o que exigiu uma reordenação na gestão e nos métodos de intervenção, bem como a ampliação dos seus serviços, programas e projetos.

Depois de promulgada a Constituição de 1988, a assistência social, conjuntamente com a Previdência e a Saúde, passa a compor o tripé da Seguridade Social brasileira. Para as entidades filantrópicas dessa época, que se mantinham praticamente com recursos privados e doações, o reconhecimento legal da assistência social permitiu um avanço significativo nas atividades e prestação de serviços. Isso porque, desde então, a assistência social, enquanto política pública passou a ter o compromisso de planejar, organizar e executar serviços e programas assistenciais, e os realiza, prioritariamente, conveniada com as entidades de beneficência. Assim, desde os 
anos 1980, a instituição B vem prestando serviços na área da assistência e educação para crianças e jovens em convênio também com o poder público, oferecendo, entre outros, o Serviço de Apoio Socioeducativo (SASE), conveniado com a FASC, da prefeitura de Porto Alegre.

Na visão da Instituição B, o SASE tem por meta contribuir na efetivação da proteção básica e integral de crianças e jovens, como preconiza a legislação brasileira. Assim, busca mobilizar seus esforços em prol da inclusão social e da plena cidadania do público que atende. Conforme o projeto pedagógico da instituição B:

a ação pedagógica engendrada visa alcançar meios de desenvolver nos sujeitos o desejo, a capacidade de sonhar e acreditar em suas capacidades, respeitando seus limites, de maneira crítica e reflexiva, sugere essa ação pedagógica a participação de todos os envolvidos em todas as suas fases de execução, desde o planejamento até os espaços de avaliação e repactuações. Oportunizar a participação dos educandos, o fortalecimento do núcleo familiar, a convivência comunitária e a construção de projetos de vida pessoal e social também são objetivos da ação pedagógica. (PPP-SASE, 2011).

A Instituição B oferece 286 vagas por ano para crianças e adolescentes na faixa etária entre 06 e 14 anos, que residam no território da comunidade e estejam em situação de vulnerabilidade social, familiar ou afetiva. As crianças e adolescentes frequentam o Programa no turno inverso ao da escola regular, nos períodos manhã e tarde. As atividades compreendem oficinas pedagógicas (reforço no conteúdo escolar), oficinas de música, desporto, de flauta, meio-ambiente, artesanato, aulas de dança, vídeo, culinária, violão e oficina de leitura. O número de oficinas realizadas chega a 4320 por ano.

O programa SASE conta com uma equipe de 06 educadores sociais (com curso superior), 02 coordenadores pedagógicos, 03 cozinheiras, 02 ajudantes gerais, 01 oficineiro, num total de 14 profissionais mantidos com 
recursos da FASC e outras fontes da própria instituição. Para além do acolhimento do público infanto-juvenil, também oferece suporte para as famílias através de uma equipe multiprofissional, que contempla pessoal da área de psicologia, pedagogia, assistência social e sociologia. Para exemplificar a rotina diária do SASE na referida Instituição, nos valemos das atividades do projeto SASE III, voltado para o público entre 12 e 14 anos. A rotina diária se divide nas seguintes ações e atividades matutinas: café, escovação; acoIhida na sala e "rodinha", para trocas de ideias, rotina pedagógica, avaliação e finalização, recreação e almoço. No turno da tarde, as atividades compreendem o almoço, escovação, acolhida na sala e "rodinha" para troca de ideias, rotina pedagógica, avaliação e finalização, recreação e lanche.

Cada educador social tem liberdade para construir o projeto pedagógico das suas turmas, levando em consideração os objetivos do Projeto Político Pedagógico da Instituição. Especificamente para o SASE III, a rotina pedagógica conta com a construção do portfólio individual de cada criança (eixo da comunicação e linguagem) desenvolvido por meio da construção textual, leitura de contos e lendas, teatro com roteiro escrito, debates, expressão das emoções (desenhos, poemas, músicas, etc.); jogos de mesa (eixo do raciocínio lógico matemático) - jogo de dama, ludo, xadrez, moinho, etc.; atividades lúdicas e esportivas (eixo da expressão corporal) - esporte na cancha (futebol, basquete e vôlei), yoga, dinâmicas de grupo, jogos lúdicos e dança; meio ambiente (eixo da exploração espacial) - visitas pelo bairro, na casa das crianças, visitas pelos pontos turísticos da capital, produção de horta para consumo dos educandos, etc.; espiritualização - (eixo das atitudes pessoais e sociais) - estudo do sagrado, meditação, atividades de prática do bem, solidariedade, oração e canto, valores humanos. As atividades são distribuídas durante a semana.

A partir da descrição das duas instituições pesquisadas é possível inferir que seus objetivos e atividades educacionais, voltadas às crianças 
sujeitas às mais diversas vulnerabilidades sociais e psicológicas, buscam o resgate da autoestima do público alvo. A pedagogia do SASE se insere no modelo da educação não formal e, portanto, ainda sem parâmetros curriculares definidos pela legislação educacional brasileira. Assim, a FASC, no caso de Porto Alegre, mas também nos demais municípios brasileiros, exige apenas uma contrapartida contratual quanto ao espaço físico e material, um mínimo de recursos humanos para o atendimento de cada grupo com 25 crianças, educadores com ensino médio, e recursos pedagógicos sem especificação clara de quantidade. O conteúdo das atividades, ações e conhecimentos teóricos e a contratação de educadores sociais especializados ficam a cargo da instituição e dependem da visão sobre a qualificação do programa e de recursos financeiros de outra origem. A inespecificidade no que se refere ao conteúdo e às atividades do programa acaba por alterar seus resultados qualitativos. Até certo ponto, isso significa que crianças e adolescentes têm recebido atendimento e conteúdos diferenciados de acordo com a instituição que frequentam, sem opção de escolha, pois o serviço é territorializado por regiões da cidade.

No entanto, mesmo sinalizados os pontos frágeis do Programa, como a ausência de normatização das atividades e conteúdos pedagógicos, precária formação dos educadores sociais e embrionária fiscalização governamental, tudo indica que o SASE, através de seus objetivos, resgata a valorização pessoal e auxilia na construção da cidadania. Destarte, tal política está umbilicalmente ligada ao processo de reconhecimento intersubjetivo e social e, portanto, ao retrocesso da violência difusa envolvendo crianças e jovens das classes populares. Nada obstante, o Serviço de Apoio Socioeducativo se encontra ainda em fase de ajustamentos e, portanto, demanda um lapso temporal para averiguação dos efeitos concretos no que se refere aos seus objetivos. 


\section{Pistas}

Tanto o material teórico quanto o empírico coletados apontam para o Serviço de Apoio Socioeducativo em meio aberto (SASE) como importante espaço institucional e pedagógico ${ }^{\square}$ de prevenção da "rualização", dos conflitos e das ações de violência social, envolvendo crianças e adolescentes urbanos expostos a situações de risco. Obtém-se tal panorama a partir dos próprios objetivos do Programa, acima já desenvolvidos, e dos depoimentos dos profissionais das instituições pesquisadas. Ao que indicam as falas dos depoentes da pesquisa, há uma percepção de que os eventos de violência, conflitos e riscos envolvendo o segmento infantojuvenil têm sua origem no âmbito intrafamiliar e recrudescem quando não há apoio comunitário e políticas públicas adequadas. Tal compreensão, sem ter origem num estudo propriamente especulativo-conceitualteórico, depreende-se mais da prática das atividades cotidianas desses profissionais, desenvolvidas no âmbito do SASE. Em virtude da abrangência dos dados coletados, propomos apresentar, no momento, apenas dois dos pontos importantes que apareceram na análise e na interpretação dos respectivos códigos descritivos.

O primeiro ponto que merece destaque remete à ênfase, dada pelos profissionais que atuam junto às crianças e aos jovens do SASE, aos desajustes nas relações familiares como importante causa das conflitualidades envolvendo esse segmento. Honneth (2009, p. 161), recorre aos estudos do psicanalista austríaco René Spitz para sinalizar que a privação da dedicação materna leva a graves distúrbios no comportamento do bebê, mesmo quando a satisfação de todas as suas carências corporais está assegurada. Por sua vez, SPITZ (2004, p. 11-12) se pergunta por que os sociólogos ignoram o fato de que, na relação mãe-filho, teriam a oportunidade de observar o início e a evolução das relações sociais, por assim dizer, in statu 
nascendi. Segundo o autor, uma relação maternal puramente biológica, sem vínculo afetivo, torna-se o modelo para as demais relações sociais do indivíduo. Relativamente aos estudos de Spitz, o autor relata que as crianças, mesmo que tratadas adequadamente quanto aos aspectos corporais como higiene, alimentação, cuidados médicos, entre outros, quando privadas do afeto materno apresentam declínio progressivo do quociente de desenvolvimento, sintomas de depressão, tornando-se emocionalmente carentes, mais agressivas e destrutivas.

Segundo dados do Sistema de Informação de Agravos de Notificação (SINAN), do Ministério da Saúde brasileiro, cerca de 40 mil casos de violência doméstica contra crianças e adolescentes na faixa etária entre 01 e 19 anos foram registrados no Sistema Único de Saúde, em 2011. No nível nacional, a faixa com maior índice de atendimento são as crianças com menos de um ano de idade. Contudo, o mais preocupante é que por baixo desse quantitativo visível, um enorme número de violências cotidianas nunca chega à luz pública (Waiselfisz, 2012, p. 62). A violência intrafamiliar pode ser entendida como

toda a ação ou omissão que prejudique o bem-estar, a integridade física e psicológica ou a liberdade e o direito ao pleno desenvolvimento de outro membro da família. Pode ser cometida dentro ou fora de casa por algum membro da família, incluindo pessoas que passam a assumir função parental, ainda que sem laços de consanguinidade, e em relação de poder à outra (Brasil, 2002, p. 15).

A negligência, o desrespeito e a falta de cuidado e afeto com as crianças e com os adolescentes por parte de suas famílias ficam evidentes na fala dos entrevistados da pesquisa. A coordenadora pedagógica da Instituição A relata o comportamento social das crianças atendidas pelo SASE:

Observamos a negligência familiar com as crianças muitas vezes na fala, muitas vezes no comportamento, na maneira de se comportar, tem coisa que a gente acha errado e 
eles acham natural, por exemplo, furtar (...). Quando eles chegam aqui, o que a gente mais vê são crianças negligenciadas, negligências que eu digo é que foram deixadas, que viveram uma vida que tu nem sabe como, nem onde, porque chegam completamente sem conhecimento ou um conhecimento completamente distorcido da vida, de tudo. Crianças que não tiveram contato com livros, não tiveram contato com brincadeiras saudáveis, parece que estavam numa caixinha fechada ou num mundo escuro só com coisas ruins, a gente meio que enxerga a maioria deles assim (Coordenadora pedagógica da Instituição A).

O diretor pedagógico da instituição B enfatiza a dificuldade do trabalho cotidiano de resgate da autoestima de crianças e jovens, porque, paradoxalmente, a teoria pedagógica é insuficiente frente às situações de extrema vulnerabilidade enfrentadas por esses.

O perfil das crianças atendidas aqui é de múltiplas vulnerabilidades, ela é muito pobre e, via de regra, mora na periferia da periferia, ela é uma criança que acessa muito pouco aos bens e serviços. Tu andando na rua tu não vês a pobreza, ostensivamente falando, tu precisas descer os barrancos para os dois lados pra enxergar os pobres, e daí elas têm problemas de esgoto, saúde pública, com recolhimento de lixo, com moradias inadequadas, moram em espaços normalmente perigosos. Mas eu acho que o problema não é só material. O grande problema tá na questão da educação das pessoas, as pessoas foram educadas para serem pobres, as pessoas foram educadas para não terem ambição de quererem alguma coisa para si, de quererem inclusive a sua educação. A grande maioria dessas pessoas viveu em lugares onde a estima delas foi roubada, como não tem estima não tem desejo. No entanto, são crianças extremamente inteligentes, uma capacidade de criar estratégias muito grandes porque vivendo na rua, vivendo na drogadição, driblando a questão do pai que é drogadito, a mãe que trabalha em situação, muitas vezes complicada, eles aprendem também a driblar as dificuldades da vida. São crianças que não é qualquer coisa que os abala aparentemente (Diretor pedagógico da Instituição B). 
A instituição B também oferece o Programa Ação Rua, conveniado com a prefeitura de Porto Alegre, cuja meta é a abordagem de crianças e jovens em situação de rua e, se bem sucedida, a reinserção dos mesmos nos respectivos núcleos familiares e/ou na rede institucional. No entendimento da coordenadora, é a falta de afeto o que movimenta uma criança a buscar a rua, pra ela buscar a rua enquanto moradia é porque na sua casa está muito mais grave, ela corre muito mais risco estando dentro de casa do que na rua (Socióloga -Ação Rua - da Instituição B).

A questão da precariedade dos cuidados às crianças por parte de suas famílias também foi recorrente nos depoimentos dos educadores sociais do SASE. Cabe aqui ilustrar com alguns depoimentos, como exemplo, os de duas educadoras da Instituição A:

a maioria das crianças os pais não se importam muito com essas coisas de como tu sentas, com quem tu andas, que horas tu entras, sabe - não tem muito essa coisa, é negligência mesmo. Eu observo isso pela forma como eles se expressam, pela forma que eles convivem com a gente tu vai vendo que eles não tiveram essa orientação em casa, isso tanto faz pra eles, eles não conhecem tais valores. Botam apelido em tudo, riem da roupa e do calçado, pra eles tanto faz sabe, amizade não tem muito, não tem aquela coisa é meu colega eu vou ajudá-lo, parceria e tal, tem crianças que não conseguem pensar no dia de amanhã. (Educadora Social da Instituição A há quatro anos)

Minha maior dificuldade é a postura deles. Eu sou chata porque eu digo pra eles que no momento que vocês saírem, convidarem vocês pra algum lugar, vocês têm postura, sabem se comportar, não é só porque se ensina na escola, não é só porque eu quero que vocês apreendam, é uma coisa que vocês vão levar pra vida de vocês, imagina se vocês forem num restaurante, na casa de um amigo, como vocês vão sentar pra comer, pra fazer um lanche, vocês não são bicho e eu quero ter orgulho, eu adoro receber elogios 
porque vocês estão bem, eu digo pra eles. (Educadora da Instituição A há um ano)

Ao mesmo tempo eu tenho que ter uma característica de mãe, tenho que ter característica de educadora, eles tem que me enxergar como educadora mas infelizmente a gente faz sim o trabalho de mãe também, sabe, porque muitos não têm as mães, não têm uma estrutura familiar, então a gente precisa dar aquele carinho de mãe, dar aquele limite de mãe, aquela brabeza de mãe, porque aqui a gente não tem conteúdo pra seguir, prova, ponto pra tirar, não, então aqui é o afeto, então tudo que a gente trabalha, os limites, as conversas é tudo pelo respeito que um tem pelo outro, eu pelos educando e eles por mim. (Educadora Social da Instituição B há um ano).

Diante do exposto, é possível inferir que políticas sociais que contemplem soluções efetivas para o planejamento familiar, maternidade e paternidade consciente, poderiam ser formuladas e executadas, por exemplo, no bojo das políticas de assistência, saúde e educação. Existem algumas experiências pontuais bem sucedidas, porém, na maioria das vezes, o tema é discutido em parcas campanhas publicitárias e oficinas comunitárias minimamente divulgadas e, por isso mesmo, com baixa frequência. Outro ponto a ser incluído no debate são as gestações de jovens meninas, quase sempre frutos da violência sexual intrafamiliar ou da deseducação para o início das relações amorosas. Ocorre que sem a consciência e a responsabilidade necessárias para a constituição de um núcleo familiar protetivo, a herança transgeracional do reconhecimento negado e da invisibilidade subjetiva e social continuará atávica para as futuras gerações.

Um segundo ponto importante a se discutir sobre o SASE e seus objetivos diz respeito aos processos pedagógicos. O Programa SASE, particularmente em Porto Alegre, iniciou suas atividades como política pública ligada à área da educação, funcionando por curto período como 
extraclasse. No fim dos anos 1990, foi integrado no bojo das políticas de assistência social, e, a partir de então, vem sendo desenvolvido e aprimorado. Importante salientar que o SASE resistiu às mudanças de governo e se tornou uma política social municipal permanente. Desde o final do ano de 2009, está vinculado ao Ministério do Desenvolvimento Social e Assistência Social como um serviço de proteção social básica, financiado pelo fundo de assistência social nacional e municipal. Flickinger (2010) elucida essa questão rocambolesca quando diz que no Brasil,

a história da educação escolar dificilmente levou em consideração a autenticidade dos processos de formação não formais, pensando muito mais no aperfeiçoamento da qualificação profissional para o trabalho, e no aumento da efetividade do ensino. Por sua vez, é a história do serviço social que é marcada pelo trabalho em campos abertos e pouco estruturados da sociedade. Desse modo, o serviço social desde sempre vem dando importância às condições sociais e políticas, determinadoras da vida daquelas camadas sociais que mais sentem os efeitos negativos do processo de modernização (Flickinger, 2010, p. 198).

Na sequência, a Resolução do Conselho Nacional de Assistência Social, CNAS n. 109, de 11 de novembro de 2009, aprovou a Tipificação Nacional dos Serviços Socioassistenciais, em conformidade com a Lei Orgânica da Assistência Social (LOAS) e com o Estatuto da Criança e do Adolescente (ECA), designando diretrizes mínimas para a implantação e funcionamento do SASE. A partir dessa resolução, os serviços de apoio socioeducativos em meio aberto passaram a ser normatizados nacionalmente pela Assistência Social e com uma nova denominação: Serviço de Convivência e Fortalecimento de Vínculos. Na prática do serviço, a alteração tem mais a ver com a necessidade de uma fonte de recursos permanente para a manutenção do serviço do que propriamente com uma proposta pedagógica. 
O SASE usa um modelo de ação híbrido, ancorado nos princípios da educação social assistemática e nas atividades assistenciais, mas apresenta lacunas ainda não resolvidas quanto à padronização e avaliação das atividades, aos conteúdos e à formação dos profissionais que nele atuam. Isso fica evidenciado na fala das educadoras sociais da instituição A e Instituição B:

eu tenho ensino médio e fiz vestibular para tecnólogo em saúde da criança e do adolescente e daí tranquei e não voltei. E tenho vários cursos de capacitação na área da violência, alguns foram oferecidos nas instituições que eu trabalhava e outros eu fiz pela FASC. Eu tranquei a faculdade na verdade foi por motivos financeiros, meu filho também estava indo pra faculdade, daí passei dificuldades financeiras e não consegui. Com certeza a gente fica muito parada, de vez em quando a gente tem que tá lendo, conversando, o tempo vai passando e tu tens que ter o cuidado de não ficar desatualizada, até a linguagem que a gente tem com eles, a gente não pode vir pra cá e ficar nas oito horas de trabalho, tem que olhar televisão, tem que ler, tem que saber o que está acontecendo, tem que se atualizar, tem que trabalhar o dia- a- dia deles, não é trabalhar só com livros, mas com a bagagem deles. Eu aproveito muito a vivência deles. (Educadora Social da Instituição A).

Tenho licenciatura em Ciências Biológicas, depois eu fiz especialização em educação ambiental e mestrado em Educação Ambiental, e logo que eu terminei o mestrado em Educação Ambiental eu comecei a trabalhar aqui. Eu tenho formação como professora, trabalhei dois anos como professora de ciências. Depois do mestrado meu primeiro emprego foi como educadora social aqui nesta instituição. Quando eu era pequena eu me lembro que na sexta série a professora apresentou o estatuto, as leis e eu lia que toda a criança tem direito à educação, eu lembro que eu lia e dizia como que tem direito e eu vejo na rua, né, eu estudava em escola particular, e então eu me admirava com aquelas crianças na minha idade na rua, fazendo coisas nas 
sinaleiras, então eu digo que aqui também é a realização de um sonho que eu tive há muitos anos atrás de ajudar essas crianças. Então, a minha formação foi vindo em direção à educação eu acho por isso, né, de eu gostar tanto de trabalhar e aprender, e eu aprendo muito, estou aprendendo aqui dia após dia a ser uma educadora social (Educadora Social da Instituição B).

O verdadeiro potencial transformador do SASE está sendo malbaratado porque focaliza seu trabalho quase exclusivamente nas ações assistenciais. Na medida em que o Programa voltar suas práticas para um modelo pedagógico orientado na educação social, usar métodos didáticos atrativos e adequados para as diferentes faixas etárias e buscar educadores qualificados e vocacionados, o objetivo de um impacto social positivo nos indicadores de vulnerabilidades, conflitualidades e transformação social poderá ser mais facilmente alcançado. São condições necessárias para isso uma valorização profissional e a qualificação dos educadores sociais, através de formação específica e continuada, e a normatização do currículo pedagógico. Fica clara, na fala das crianças e dos adolescentes do SASE, a necessidade de readequar conteúdo e metodologia didática.

Eu gostava de fazer biscuit, e ir para o pátio brincar. Jogar bola. Eu gostava de jogar futebol. Os passeios e a informática. Gostava das piscinas, mas eu não me lembro do nome do lugar das piscinas, ah! Itapema Park. Eu gostava da praça e dos passeios. Eu também, praça e passeio. Não gostava de entrar pra sala de aula. Eu preferia ficar no pátio. Gostava de desenhar e fazer brincadeiras. De melhor tinha o pátio. As aulas de flauta era o que eu menos gostava, era chato, mas participava só quem quisesse, eu não fazia, eu gostava era dos passeios. Não gostava de entrar pra sala e escrever, a professora passava coisas sobre drogas, lá, a gente reclamava pra ela. A gente tinha que escrever no colégio e no curso também, né, tá louco, ela passava um monte de coisa no quadro e a gente tinha que anotar. Melhor era a praça e os passeios. Eu também achava ruim entrar pra sala 
e escrever um monte de coisas, tinha que escrever muito, porque é chato, a gente poderia ficar brincando e tinha que ficar discutindo assuntos de adolescentes. Pra mim o SASE é ficar brincando no pátio, não tem idade pra discutir isso. (Fragmentos de falas dos adolescentes egressos da Instituição B, via grupo focal).

Eu gosto de fazer os temas da escola e gosto de fazer relaxamento, mexer os dedos, mexer o corpo devagar, fazer massagem um no outro. Eu gosto de brincar no pátio, gosto de fazer relaxamento e os temas. Eu gosto de jogar "três corta", e eu gosto da tia, gosto também de quebra-cabeças. Eu gosto também de ler, a gente que pega os livrinhos e lemos - cada um pega um e lê. Eu gosto também do artesanato, toda a segunda a gente têm aula de arte. A gente faz coisas com biscuit e faz também uns vidrinhos. Sobraram uns vidrinhos, seriam pras mães, mas algumas mães não vieram. Eu gosto de fazer o tema. Sim, também gosto de "três corta" e brincar no pátio, e da pracinha também. Gosto de andar de balanço, brincar de "três corta" e desenhar. Eu gosto de fazer os temas, brincar, ir pra pracinha e também de jogar bola. Gosto do balanço, jogar futebol e "três corta" também. Eu gosto de vir para o SASE porque minha mãe não deixa eu ficar muito na rua porque tem muito tráfico de drogas alí na frente e quando eu não estou aqui eu fico na minha tia. Nunca falto no SASE, eu prefiro vir pro SASE do que ficar aprendendo coisa ruim na rua. Eu gosto de vir para o SASE porque não tem ninguém pra eu ficar lá na vila. Eu gosto de vir para o SASE porque se eu fico em casa minha mãe me manda limpar a casa (risos de todos). Eu gosto de vir para o SASE porque não tem ninguém em casa e eu fico sozinha. (Fragmentos das falas de crianças participantes do SASE na Instituição A, via grupo focal).

Sinalizamos, ainda que de forma sutil, um último ponto a ser repensado para a qualificação do Serviço. O acompanhamento dos egressos por um período determinado, pela própria instituição de origem, quanto ao acesso à educação continuada, inserção no mercado de trabalho e 
convívio comunitário e familiar, certamente se faz necessário. Cercar-se dessas informações apontaria lacunas ainda não identificadas, e, à medida que saneadas, ampliariam os horizontes de possibilidades para novos recursos e medidas institucionais de tal política pública, no que se refere ao resgate do reconhecimento social e subjetivo de crianças e jovens em situação de vulnerabilidades.

Para finalizar o estudo, seguindo a linha metodológica de LessardHébert e coautores (2005), o polo morfológico foi construído a partir das informações coletadas e trabalhadas nos três polos anteriores. Mesmo numa perspectiva hermenêutica, ainda que, inadvertidamente, se possa imaginar ausência de métodos, ao contrário, trata-se de adequar a medida ao objeto e fazer a devida distinção e uso da forma e do conteúdo. Nesse diapasão, os resultados, sempre a considerar o fator inconcluso e transitório dos mesmos, foram socializados em forma de relatório e artigos.

\section{Reflexões finais}

A partir dos resultados dessa investigação, considerada sua especificidade metodológica, a teoria do reconhecimento social e intersubjetivo como fundamento para a compreensão do fenômeno de "irresidência" infanto-juvenil e consequentes conflitos urbanos corroborou a hipótese do não reconhecimento como causa importante da violência urbana envolvendo o segmento infanto-juvenil. Ao que tudo indica, parece que compreender a causa da "rualização" de crianças e adolescentes e a consequente violência urbana pelo critério isolado da pobreza econômica é a mais frágil e incompleta das interpretações. Na mesma trilha do presente estudo, citamos o trabalho de Gratius \& Valença (2011), que mostra as diferentes perspectivas quanto à explicação da violência na cidade de Caracas, capital da Venezuela. Desde 1999, o governo, cuja plataforma 
política se baseia na igualdade social, tenta explicar as raízes da violência como consequência da pobreza, enquanto que, paradoxalmente, verifica-se o aumento dos conflitos urbanos mesmo depois de grande aporte assistencial. O estudo demonstra que políticas assistencialistas desarticuladas das políticas de educação, direitos humanos e reforma policial não logram êxito no combate aos conflitos e à violência urbana. De outro lado, lembramos o caso da Alemanha. Apesar do crescente fluxo de recursos aplicados na assistência social, os índices de violência urbana têm se mantido, excetuando-se algumas variantes, no mesmo patamar, relativamente a ultima década.

Nessa perspectiva é que Honneth entende que a deflagração dos conflitos sociais se dá a partir das experiências humanas de menosprezo, humilhação e discriminação e não meramente por questões econômicas. Noutras palavras, o autor faz uma leitura em que, na atualidade, o mais alto propósito de integrar um determinado grupo de reivindicação é encontrar um meio social de reconhecimento da valoração pessoal (Honneth, 2010c, p. 269). Tampouco, os sujeitos buscam meramente o reconhecimento jurídico, imposto e forçado, mas reivindicam a valorização social livre, como sujeitos de direitos subjetivos (Honneth, 2010b, p. 56-58).

Quando sujeitos imbuídos do sentimento de raiva, que se manifesta reverberando mágoa, ressentimento e rancor, se deparam com o sentimento coletivo de injustiça, então germina o propelente detonador dos conflitos urbanos. De outro lado, Misse também alerta sobre a superficialidade da associação entre pobreza e violência urbana, quando escreve que não é exatamente a pobreza que leva ao crime, mas pode ser a revolta (Misse, 2006, p. 10). Na mesma linha, Tavares dos Santos e Machado (2010) apontam as rupturas dos laços sociais e familiares que fragilizam ou interrompem o vínculo entre o "eu e o outro", como pontos fundamentais para a compreensão das conflitualidades. 
Talvez uma característica atual do jovem adolescente seja a incerteza da vida, assim como o exercício e a experiência da violência representam uma ruptura do contrato social e dos laços sociais, levando a fenômenos de 'desfiliação', quebrando as relações de alteridade e rasgando a ligação entre o eu e o outro (Tavares dos Santos; Machado, 2010, p. 241).

Reiteramos que não foi meta desse artigo o debate e confrontação entre teorias. Estamos cônscios das limitações apontadas pelos interlocutores críticos da teoria do não reconhecimento social. Todavia, não se configuram mais em exceções as diagnoses não materialistas como causa dos conflitos urbanos. Parte-se dessa assertiva, para abordar o SASE enquanto política assistencial básica, orientada por princípios morais, afetivos e pedagógicos específicos, voltada para o segmento infanto-juvenil oriundo de famílias em situação de vulnerabilidade social, como um programa relevante, capaz de oportunizar o desenvolvimento humano-social do público-alvo. O Programa, na sua essência, tem por meta oferecer as ferramentas necessárias para o empoderamento pessoal, intelectual e político, através do resgate da autoestima, da consciência dos direitos e da pertença social. No entanto, para melhor qualificá-lo, entendemos que tal política suscita prescrever uma formação adequada para os profissionais da equipe de educadores sociais, normatizar um currículo pedagógico comum e aperfeiçoar os mecanismos de avaliação e de fiscalização, tornando-os compulsórios para todas as instituições conveniadas ofertantes do SASE.

Com efeito, temas contemporâneos e complexos como o da violência urbana e das conflitualidades envolvendo crianças e jovens não se esgotam, ao contrário, carecem sempre de mais investigações. Neste artigo, em especial, procuramos problematizar sobre as origens dos conflitos sociais que cercam o segmento infanto-juvenil, particularmente a "rualização" e a violência gerada por ela. Diante da atual profusão das conflitualidades urbanas, é importante sinalizar que a sociologia do segundo 
milênio cumprirá sua missão quanto menos dicotomizar pensamento e ação, e mais empreender o labor interdisciplinar, o agir e o comprometimento social. De fato, numa perspectiva sociológica factual, teorias simbióticas, como, por exemplo, a de Axel Honneth, têm muito a contribuir para a consolidação de uma sociologia microssocial, onde a vida vivida, e não a teorizada, definitivamente acontece e transforma a sociedade.

\section{Referências}

BARBOUR, Rosalina. Grupos Focais. Porto Alegre: Artmed, 2009.

BRASIL. Secretaria de Políticas de Saúde. Violência Intrafamiliar. Orientações para a prática em serviço. Cadernos de Atenção Básica n. 8. Brasília: Ministério da Saúde, 2002.

BRASIL. Secretaria Especial dos Direitos Humanos. Mapeamento Nacional das Medidas Socioeducativas em Meio Aberto. Brasília, 2007.

BRASIL. Resolução n. 109 de 11 de novembro de 2009. O Conselho Nacional de Assistência Social (CNAS) resolve sobre os incisos, de sua competência, II, V, IX e XIV do artigo no 18 da Lei no 8.742, de 7 de dezembro de 1993, Lei Orgânica da Assistência Social (LOAS), aprovar a Tipificação Nacional dos Serviços Socioassistenciais. Diário Oficial da República Federativa do Brasil, Brasília, DF, n. 225 , 25 de novembro de 2009. Seção I.

FLICK, Uwe. (org). Coleção Pesquisa Qualitativa. Porto Alegre: Artmed, 2009.

FLICKINGER, Hans Georg. A Caminho de uma Pedagogia Hermenêutica. Campinas: Autores Associados, 2010.

FRAGOSO, Suely; RECUERO, Raquel; AMARAL, Adriana. Métodos de Pesquisa para Internet. Porto Alegre: Sulina, 2011.

FUHRMANN, Nadia. A Busca pelo Reconhecimento Intersubjetivo e Social Recusado do Segmento Infanto-juvenil em Situação de Rua. Um estudo sobre o Serviço de Apoio Socioeducativo (SASE), da Prefeitura de Porto Alegre. Relatório de Pesquisa, Porto Alegre, PPG-Sociologia, UFRGS/ CNPq, 2011.

GADAMER, Hans -Georg. Wahrheit und Methode. Grundzüge einer philosophischen Hermeneutik. Tübingen: Mohr, 1990.

GADAMER, Hans -Georg. Wahrheit und Methode. Erganzungen Register. Tübingen: Mohr, 1993. 
GEHLEN, Ivaldo. (Org). Perfil e Mundo das Crianças e Adolescentes em Situação de Rua na Grande Porto Alegre. Relatório Final de Pesquisa. Porto Alegre: Instituto de Filosofia e Ciências Humanas da UFRGS, 2004.

GEHLEN, Ivaldo. Cadastro de Crianças, Adolescentes e Adultos em Situação de Rua e Estudo do Mundo da População Adulta em Situação de Rua de Porto Alegre/RS. Relatório Final de Pesquisa. Porto Alegre. Instituto de Filosofia e Ciências Humanas da UFRGS, 2008.

GRATIUS, Susanne; VALENÇA, Marcelo. Violência Urbana em Caracas e no Rio de Janeiro: respostas locais e europeias. Madri: FRIDE, 2011.

HONNETH, Axel. Kampf um Anerkennung. Zur moralischen Grammatik Sozialer Konflikte. Frankfurt am Main: Suhrkamp, 1992.

HONNETH, Axel. Democracia como Cooperação Reflexiva. John Dewey e a teoria democrática hoje. In: SOUZA, Jessé. (org). Democracia Hoje. Novos desafios para a teoria democrática contemporânea. Brasília, UNB, 2001.

HONNETH, Axel. Patologias da Liberdade Individual. $\mathbf{O}$ diagnóstico hegeliano de época e o presente. Novos Estudos CEBRAP, São Paulo, n. 66, p. 77-90, 2003. HONNETH, Axel. Sofrimento de Indeterminação. São Paulo: Esfera Pública, 2007. HONNETH, Axel. Reificación. Un Esdudio em la Teoría del Reconocimiento. Buenos Aires: Katz, 2007.

HONNETH, Axel. Pathologien der Vernunft. Geschichte und Gegenwart der Kritischen Theorie. Frankfurt am Main: Suhrkamp, 2007.

HONNETH, Axel. Reconhecimento ou Redistribuição? A mudança de perspectiva na ordem moral da sociedade. In: SOUZA, Jessé; MATTOS, Patrícia. (orgs) Teoria Crítica no Século XXI. São Paulo: Annablume, 2007.

HONNETH, Axel. Luta por Reconhecimento. A gramática moral dos conflitos sociais. 2 ${ }^{a}$ ed. São Paulo: Editora 34, 2009.

HONNETH, Axel. Critica del Poder. Fases en la reflexión de una Teoría Crítica de la Sociedad. Madrid: A. Machado Libros, 2009b.

HONNETH, Axel. The Pathologies of Individual Freedom. Hegel's social theory. Princeton: PrincetonUniversity Press, 2010.

HONNETH, Axel. Reconocimiento y Monosprecio. Sobre la fundamentación normativa de una teoria social. Madrid: Katz, $2010 \mathrm{~b}$.

HONNETH, Axel. Das Ich Im Wir. Studien zur Anerkennungstheorie. Berlin: Suhrkamp, 2010c.

HONNETH, Axel. Das Recht der Freiheit. Grundri $\square$ einer demokratischen Sittlichkeit. Berlin: Suhrkamp, 2011. 
LAWN, Chris. Compreender Gadamer. Petrópolis: Vozes, 2007.

LESSARD-HÉBERT, Michelle; GOYETTE, Gabriel; BOUTIN, Gerald. Investigação Qualitativa: fundamentos e práticas. 2ª ed. Lisboa: Instituto Piaget, 2005.

LUSK, M. W: MASON, D. T. Meninos e Meninas "de rua" no Rio de Janeiro. Um estudo sobre sua tipologia. In: RIZZINI, Irene. (org.) A criança no Brasil hoje: desafio para o terceiro milênio. Rio de Janeiro: Universitária Santa Úrsula, 1993.

MISSE, Michel. Crime e Pobreza: velhos enfoques, novos problemas. In: Crime e Violência no Brasil Contemporâneo. Rio de Janeiro: Lumen Juris, 2006.

SABATOVSKI, Emílio; FONTOURA, Iara. Estatuto da Criança e do Adolescente. 5a ed. Curitiba: Juruá, 2010.

SPITZ, René. O Primeiro Ano de Vida. São Paulo: Martins Fontes, 2004.

TAVARES DOS SANTOS, José Vicente. As Possibilidades das Metodologias Informacionais nas Práticas Sociológicas: por um novo padrão de trabalho para os sociólogos do século XXI. Sociologias, Porto Alegre, ano 3, n. 5, p. 116 -148, 2001.

TAVARES DOS SANTOS, José Vicente. As Lutas Sociais contra as Violências, Revista Política e Sociedade, Porto Alegre, v. 6, n. 11, p. 71-100, 2007.

TAVARES DOS SANTOS, José Vicente. Violências e Conflitualidades. Porto Alegre: Tomo Editorial, 2009.

TAVARES DOS SANTOS, José Vicente; BAUMGARTEN, Maira. Contribuição da Sociologia na América Latina à Imaginação Sociológica: análise, crítica e compromisso social, Revista Sociologias, Porto Alegre, n. 14, p. 178-243, 2005.

TAVARES DOS SANTOS, José Vicente et all. (orgs.) Mundialização e Sociologia Crítica da América Latina. Porto Alegre: UFRGS, 2009.

TAVARES DOS SANTOS, José Vicente et all. (orgs.) Democracia, Violências e Lutas Sociais na América Latina. Porto Alegre: UFRGS, 2009.

TAVARES DOS SANTOS, José Vicente; MACHADO, Elisabeth Mazeron. Violência, Juventude e Reconstrução dos Laços Sociais. Revista Brasileira de Psicoterapia, Porto Alegre, v. 12, p. 238-251, 2011.

TAVARES DOS SANTOS, José Vicente; TEIXEIRA, Alex Niche; RUSSO, Maurício. (orgs). Violência e Cidadania. Práticas Sociológicas e Compromissos Sociais. Porto Alegre: UFRGS; Sulina, 2011.

WAISELFISZ, Julio Jacobo. Mapa da Violência 2012. Crianças e Adolescentes no Brasil. Rio de Janeiro: FLACSO, 2012.

Recebido em: 19/03/2013

Aceite final: 08/07/2013 